\title{
Effect of Aerosolized Uridine-5'-Triphosphate on Airway Clearance with Cough in Patients with Primary Ciliary Dyskinesia
}

\author{
PEADAR G. NOONE, WILLIAM D. BENNETT, JEFF A. REGNIS, KIRBY L. ZEMAN, JOHNNY L. CARSON, \\ MALCOLM KING, RICHARD C. BOUCHER, and MICHAEL R. KNOWLES
}

Division of Pulmonary Medicine, Department of Medicine, University of North Carolina at Chapel Hill, Chapel Hill, North Carolina; and The University of Alberta, Edmonton, Alberta, Canada

\begin{abstract}
Primary ciliary dyskinesia (PCD) is a genetic disease characterized by abnormal ciliary structure and function and impaired mucociliary clearance. Because patients with PCD use cough clearance as an airway defense mechanism, we tested the hypothesis that aerosolized uridine-5'-triphosphate (UTP) would improve clearance during cough by its actions to stimulate $\mathrm{Cl}^{-}$secretion and mucin release by goblet cells. We measured clearance during cough in 12 patients with PCD (ages 14 to 71 yr, FEV $43 \%$ to $89 \%$ predicted) in a double blind, randomized, crossover study after aerosolization of a single dose of UTP $(5 \mathrm{mg} / \mathrm{ml}, 3.5 \mathrm{ml})$ or vehicle $(0.12 \%$ saline, $3.5 \mathrm{ml})$. Clearance during cough (whole lung) was quantified during and after a series of controlled coughs by measuring the clearance of [ ${ }^{99 \mathrm{~m}} \mathrm{Tc}_{\mathrm{Fe}} \mathrm{O}_{3}$ particles via gamma camera scanning over $120 \mathrm{~min}$. Safety parameters were recorded during and after drug delivery. Aerosolized UTP improved whole-lung clearance during cough as compared with vehicle (from 0 to $60 \mathrm{~min}: 0.40 \pm 0.07 \% / \mathrm{min}$ [UTP] versus $0.26 \pm 0.04 \% / \mathrm{min}$ [vehicle] [mean \pm SEM], $p=0.01$ ), and from 0 to $120 \mathrm{~min}: 0.38 \pm 0.05 \% / \mathrm{min}$ [UTP] versus $0.25 \pm 0.04 \%$ / $\min$ [vehicle], $p=0.02$ ). Aerosolized UTP is safe, with no serious adverse effects. Whole-lung clearance during cough in patients with defective ciliary function is enhanced after inhalation of UTP. Noone PG, Bennett WD, Regnis JA, Zeman KL, Carson JL, King M, Boucher RC, Knowles MR. Effect of aerosolized uridine-5'-triphosphate on airway clearance with cough in patients with primary ciliary dyskinesia.

AM J RESPIR CRIT CARE MED 1999;160:144-149.
\end{abstract}

Primary ciliary dyskinesia (PCD) is a genetic disease characterized by abnormal ciliary ultrastructure and function, impaired mucociliary clearance, and chronic lung, sinus and middle ear disease $(1,2)$. Patients with PCD depend on cough for airway clearance, and the cornerstone of the treatment of $P C D$ is mechanical clearance of airway secretions (3-6). A erosolized uridine-5'-triphosphate (UTP) improves mucociliary clearance (MCC) in normal individuals and, when used in combination with amiloride, in patients with $\operatorname{CF}(7,8)$. The actions of UTP on MCC are mediated by activation of a noncystic fibrosis transmembrane regulator (CFTR) $\mathrm{Cl}^{-}$conductance via $\mathrm{P}_{2} \mathrm{Y}_{2}$ receptors, and by increases in intracellular

(Received in original form June 26, 1998 and in revised form February 10, 1999) Supported in part by grants HL34322, HL42384, HL56395, and RR00046 from the National Institutes of Health, grant CFF L543 from The Cystic Fibrosis Foundation, Inspire Pharmaceuticals Inc., and the Winston Churchill Memorial Trust of Australia.

Drs. Richard C. Boucher and Michael R. Knowles are founding scientists of Inspire Pharmaceuticals, which licensed the patent for aerosolized uridine-5'-triphosphate from the University of North Carolina on March 10, 1995. Drs. Boucher and Knowles and the University of North Carolina hold equity in Inspire Pharmaceuticals.

Correspondence and requests for reprints should be addressed to Peadar G. Noone, Pulmonary Division, CB \#248, The University of North Carolina at Chapel Hill, Chapel Hill, NC 27599-7248.

Am J Respir Crit Care Med Vol 160. pp 144-149, 1999

Internet address: www.atsjournals.org calcium, to stimulate ciliary beat frequency, (CBF) release mucin from goblet cells, and induce $\mathrm{Cl}^{-}$secretion (9-11).

Triphosphate nucleotides do not stimulate the defective cilia in PCD, but might favorably affect cough-clearable airway secretions via modulation of the liquid and mucin content of airway secretions. A nother way of stating this is that patients with PCD provide a genetic model for testing whether UTP may affect nonciliary aspects (ion transport, mucins) of the clearance of airway secretions during cough. The aim of the present study was to evaluate the safety and biologic efficacy of UTP, delivered in an aerosol to patients with PCD, in assisting clearance during cough. UTP has been shown to be safe and effective in normal subjects and patients with lung disease (cystic fibrosis; CF) $(7,8)$. A s a measure of biologic efficacy, we tested the effects of UTP on the rate of clearance during cough of radiolabeled insoluble particles from the airways, with predetermined periods of "controlled" (directed) coughing by the subjects.

\section{METHODS}

\section{Study Subjects}

We studied 12 patients with PCD (four males and eight females). The patients' mean age was $34 \mathrm{yr}$ (range: 14 to $71 \mathrm{yr}$ ) and their mean FEV 1 was $65.5 \%$ predicted (range: $43 \%$ to $89 \%$ predicted). A II subjects had clinical and radiologic evidence of bronchiectasis; five subjects had situs inversus totalis. A II subjects were in a stable clinical state upon entering and finishing the study, although all had a stable chronic cough 
productive of variable reported amounts of sputum. Subjects were excluded if they were considered to have significant intercurrent infection, defined as a change in cough or sputum production or increased dyspnea within 2 wk of screening. No patients had any history suggestive of significant asthma. A s a part of the study protocol, all subjects were treated with oral antibiotics (appropriate to their respiratory flora) for 1 wk before the study. Subjects were asked to withhold inhaled and oral bronchodilators on the morning of a study day, but continued other medications and physical therapy as usual.

Screening included a complete history and physical examination, together with a chest radiograph, lung function tests ( $F E V_{1}, F V C$, $F E F_{25-75}$ ), routine screening blood tests, an electrocardiogram (ECG), and a pregnancy test in females. Samples of cilia were obtained by the nasal scrape biopsy technique, and ciliary ultrastructural abnormalities were proven by electron microscopic studies (12).

Informed consent was obtained under the auspices of the Committee on the Protection of the R ights of $\mathrm{H}$ uman Subjects of the $\mathrm{U}$ niversity of N orth Carolina at Chapel $\mathrm{H}$ ill.

\section{Drug Preparation and Storage}

A $10 \%$ stock solution of U TP was prepared for administration by dissolving dry uridine-5-triphosphate powder (98.9\% UTP; Plenum Scientific R esearch Inc., H ackensack, NJ and Inspire Pharmaceuticals, Research Triangle Park, NC) in $0.12 \%$ saline. A liquots of $0.22 \mathrm{ml}$ of stock solution were kept frozen at $-20^{\circ} \mathrm{C}$ until the day of the study, when they were each thawed and diluted with $3.78 \mathrm{ml} 0.12 \%$ saline to achieve a $4 \mathrm{ml}$ volume of the appropriate concentration $(5 \mathrm{mg} / \mathrm{ml})$ for administration. To ensure that the investigators remained blinded, aliquots of stock UTP and vehicle solution ( $0.12 \%$ [hypotonic] saline) were paired, labeled by an unblinded observer, and kept under the same conditions. The final volume of both UTP and vehicle placed in the nebulizer for aerosolization was $3.5 \mathrm{ml}$ (i.e., $0.5 \mathrm{ml}$ of the $4 \mathrm{ml}$ was discarded after achieving the final concentration described earlier).

\section{Study Design}

The study was a double-blind crossover study conducted on two separate days with at least $48 \mathrm{~h}$ between study days to ensure sufficient clearing of radionuclide marker. A fter labeling of their airways with

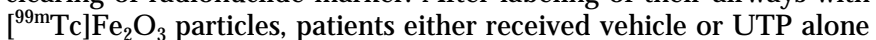
on the first study day, followed by the alternate solution on the second study day. A scan was performed at $24 \mathrm{~h}$ to assess residual deposition. Delivery was double-blinded by labeling the appropriate vial with a randomization code drawn up by an independent observer, and by following a preordained, computer-generated, random sequence of delivery. Following study completion, it was verified that all patients received the appropriate assigned study drug treatment. Figure 1 illustrates the study protocol in outline form, with the time points of the various interventions.

\section{Drug Delivery and Measures of Clearance During Cough}

Prior to inhalation of study solution on Day 1 , a xenon-133 equilibrium scan was obtained for each subject as a reference image of the

Intermittent lung scanning

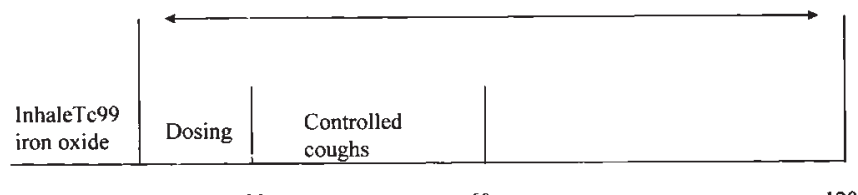

$-3 \quad 0 \quad 20$

60

120

Time (min)

Figure 1. Schematic outline of cough-clearance protocol for each study day, denoting time points and interventions. Time $=0$ represents the start of study-solution inhalation. The total number of coughs (spontaneous plus controlled) was 90 during the initial 60 min scanning interval. whole lung, for defining regions of interest (R OIs) related to the deposition and clearance of marker, and for calculating central-to-peripheral (C/P) deposition ratios for each study day $(7,8)$. On all study days, a background scan was done for $15 \mathrm{~min}$ to determine background gamma counts. Following the background scan on each study day, each subject inhaled a monodisperse preparation of [ $\left.{ }^{99 \mathrm{~m}} \mathrm{Tc}\right] \mathrm{Fe} \mathrm{e}_{2} \mathrm{O}_{3}$ particles ( $4.5 \mu$ mass median aerodynamic diameter [M MA D ], 1.25 geometric standard deviation [GSD ]; M allinckrodt, St. Louis, M O) generated by a spinning top generator (13). Deposition on different days was matched by controlling tidal flow $(500 \mathrm{ml} / \mathrm{min})$ and breathing frequency (15/min). This was achieved by having the patient monitor tidal flow and frequency on an oscilloscope. Inhalation was stopped when $\sim 25 \mu \mathrm{Ci}$ was deposited in the lungs, a dose sufficient for clearance measurements. The subjects then moved to sit in front of the gamma camera (A pex 415, interfaced with an Elscint Model 109 computer [E Iscint, I srael]) for two initial 2-min scans. I mmediately after these scans, the subjects inhaled the solution ( $3.5 \mathrm{ml}$ ) coded for that day by nebulization (M MA D $\sim 5 \mu$ ) over a 17- to 20-min period via a finger-activated jet nebulizer ( $M$ odel 646; $\mathrm{D} \mathrm{eV}$ ilbiss $\mathrm{H}$ ealthcare Inc., Somerset, PA ) powered by a compressed air generator (D eV ilbiss Pulmo-A ide M odel 5610D ; flow rate 7 to $9 \mathrm{~L} / \mathrm{min}$ ). The breathing pattern of inhalation was predefined to optimize deposition of drug on airway surfaces: for each cycle, initial exhalation to FRC was followed by finger activation of the nebulizer and slow inhalation of the aerosol to TLC over a period of 3 to $4 \mathrm{~s}$, with a 3- to 4-s breath hold, and slow exhalation over a 3- to 4-s period. A II subjects breathed in this manner without difficulty at a breathing cycle of $\sim 5$ to 6 breaths/ $\min$ for $\sim 18$ to $20 \mathrm{~min}$. Nebulization was stopped when an aerosol cloud was no longer visibly produced by the nebulizer. A this point, a dead volume of $\sim 0.5 \mathrm{ml}$ was left in the nebulizer.

During the $2 \mathrm{~h}$ after inhalation of the radiolabeled marker, subjects sat in front of the gamma camera and sequential 2-min images were obtained (two 2-min images for the first 4 min of every 10-min period) (Figure 1). D uring inhalation, and for $30 \mathrm{~min}$ afterward, blood pressure, heart rate ( $\mathrm{HR}$; by ECG), and oxyhemoglobin $\left(\mathrm{Sa}_{\mathrm{O}_{2}}\right)$ saturation were monitored in nine of the 12 subjects. Following all study days, the subjects returned at $24 \mathrm{~h}$ for a 30 -min scan for evaluation of residual marker deposition.

\section{Controlled Coughs}

Previous data suggested that, as predicted, there is no M CC in patients with PCD without cough $(3,4,14)$. To determine baseline clearance under the laboratory conditions at the $U$ niversity of N orth Carolina, and the effect of UTP versus vehicle, we performed pilot studies of four patients with $P C D$, measuring clearance after aerosolization of either UTP or vehicle in the same fashion as that described earlier. There was little or no baseline clearance in any of the subjects in the absence of cough with either vehicle or UTP. These data, coupled with those from the literature, support the notion that nucleotides (UTP) do not stimulate CBF/M CC in PCD in the absence of cough, and that cough may be used as an outcome measure to assess clearance during cough following an intervention such as aerosolized delivery of drug in comparison with vehicle $(3,14)$. The pilot data also suggested that some patients might not be able to completely suppress cough during and immediately after aerosol inhalation. We therefore elected to study clearance during a series of controlled coughs from $t=$ 20 to $60 \mathrm{~min}$ ( $\mathrm{t}=0$ to $20 \mathrm{~min}$ represents the period of delivery of solution). Some patients coughed spontaneously during and after inhalation of study drug; these coughs were counted; the total number of coughs (spontaneous plus controlled) was limited to 90 during the 60 min time period (e.g., if a subject coughed spontaneously 15 times, 75 controlled coughs were performed). Controlled coughs were performed by having each subject cough under the direction of the investigators into a spirometer. Flow was displayed on an oscilloscope, so that the subject could follow the same expiratory flow pattern as closely as possible during each cough. The peak flow rate (PFR; $L / S$ ) of each controlled cough was recorded on a $M$ acintosh computer ( $A$ pple Computer, Cupertino, CA ) using a data acquisition system ( $\mathrm{M}$ aclab; A pple). When available for collection, sputum was obtained during these cough maneuvers as soon as possible after aerosol delivery was completed, and the time taken to produce the sample was recorded (minutes). The sputum was collected in a manner designed to 
minimize salivary contamination, using the dental cotton technique. In addition, the time elapsed between the start of the study and sputum production was measured. The sputum was double wrapped in Parafilm and frozen at $-80^{\circ} \mathrm{C}$ pending studies of sputum weights, ion content, and rheologic tests. The last of these were performed with the magnetic oscillating sphere technique, and the sputum was analyzed for $\mathrm{Na}^{+}, \mathrm{K}^{+}$, and $\mathrm{Cl}^{-}$content $(16,17)$. Included in these measures were A vg Log G (an index of the mechanical impedance of sputum); the MCC index and cough-clearance index were calculated. These are unitless measures predicted from model cough and M CC studies in normalized systems, and predict mucus clearability by ciliary and cough mechanisms on the basis of measured rheologic properties and observations in model studies (18).

\section{Data Acquisition}

The xenon-133 equilibrium scan at baseline was used to create R O Is for each subject, focused on the whole lung as well as on central and peripheral regions, to determine regional deposition and clearance patterns $(7,8)$. A rectangular region bordering the whole right lung (to avoid activity in the stomach, was used to determine by computer analysis the lung retention ( $R$ ) of radiolabeled particles in the right lung over the 2 - $h$ period and at $24 \mathrm{~h}$, expressed as a percent of the initial counts at time $=0$. If a subject had situs inversus, the left lung was analyzed to avoid activity in the right-sided stomach. A CP ratio of deposition, normalized to the xenon equilibrium scan, was calculated to assess the uniformity of deposition on the various study days. To calculate $R$ at a given time, the first two images of each scanning period were averaged at that time. R etention curves were constructed for each study day from background readings and decay rates, with the counts corrected at 10-min intervals and normalized to the background-corrected counts at $t=0$ (when $\mathrm{R}=100 \%$ by definition). Clearance was calculated from these data as ( 1 - retention). The mean percent radioactivity cleared was calculated by averaging the percent cleared for each 10-min time period within the period of interest ( 0 to $60 \mathrm{~min}$ and 0 to $120 \mathrm{~min}$ ). A dditionally, clearance was calculated as the percent isotope cleared per minute (\%/min), by dividing the mean clearance by the mean time for these time periods. It should be noted that 20 to $60 \mathrm{~min}$ was the period of controlled cough, and that 0 to $120 \mathrm{~min}$ was the total observation period. The clearance data were calculated for whole and peripheral lung regions, using the ROIs as described previously.

\section{Sputum Expectoration/Symptoms}

B efore and after aerosol dosing, patients were asked to score, on a questionnaire sheet, the severity and type of their cough, amount, ease of expectoration, and nature of sputum, chest tightness, and wheezing, on a scale of 0 to 10 . They were also asked to record comments about any symptoms or feelings in the chest after inhalation.

\section{Data Analysis}

To test the hypothesis that aerosolized UTP would significantly enhance whole-lung clearance, we compared the mean clearance rates $(\% / \mathrm{min})$ in individual patients, using a two-tailed paired t test for U TP versus vehicle, during the specified of time periods of 0 to $60 \mathrm{~min}$ and 0 to 120 min. B ecause differences in C/P ratios between the two study days might have produced differences in mean clearance, independent of any U TP effect, we also compared the C/P ratio on each study day (UTP versus vehicle), using a two-tailed paired t test. A s a secondary analysis, we used multivariate analysis with stepwise entry of data to examine the differences in clearance on each study day as a function of: (1) study drug (UTP versus vehicle), (2) C/P ratio; (3) the percent of the total number of coughs that were spontaneous; (4) the PFR (L/S) of controlled coughs; and (5) the subject characteristics $\left(F E V_{1}\right.$, age, sex). These evaluations were done through analysis of variance, using Systat for M acintosh (Systat Inc., E vanston, IL) and the Sigmastat program. A Ithough it has not been shown experimentally in vivo that as variables either spontaneous and controlled coughs or the PFR of coughs as variables significantly affect clearance during cough in patients with PCD, theoretical considerations and model experiments suggest that they may be important determinants of cough efficacy $(17,19)$. The questionnaires were compared for each study day for the whole group, and were also compared qualitatively.
The total sputum weights were compared for each study day. In addition, the time taken to produce the sputum was analyzed, and a sputum "production rate" was calculated and compared for each study day (i.e., if a subject produced $X$ grams of sputum $Y$ minutes after the commencement of the study, the sputum production rate was calculated as $X / Y$ grams per minute for that individual. The data were compared for the entire group for each study day. I on content and indices of rheology for matched pairs of sputum (obtained after UTP and vehicle) were compared on the basis of the following parameters: A vg Log G; cough clearance index (CCl); MCC index ( $\mathrm{MCl})$; and $\mathrm{Na}^{+}, \mathrm{K}^{+}$, and $\mathrm{Cl}^{-}$content (17). Safety data (HR, oxyhemoglobin saturation as $\mathrm{Sa}_{\mathrm{O}_{2}}$, and blood pressure) were also analyzed for subjects at baseline and at $15 \mathrm{~min}, 30 \mathrm{~min}$, and $45 \mathrm{~min}$. The sputum and safety data described here were compared through a two tailed paired test; results are expressed as mean \pm SE M, with significance for all statistical analyses set at $p<0.05$.

\section{RESULTS}

\section{Clearance during Cough (Whole Lung)}

Clearance curves representing mean whole-lung clearance of 99m[T C]F $\mathrm{e}_{2} \mathrm{O}_{3}$ for both vehicle and UTP $(n=12)$ are illustrated in Figure 2. Coughing clearly increased the rate of whole-lung clearance of particles from $t=20$ to $60 \mathrm{~min}$. There was an early separation between the clearance curve for vehicle and that for UTP, which increased for the 60 min of controlled and spontaneous coughing and was maintained for the entire study time (120 min). It was also obvious that when there was little or no cough (after $60 \mathrm{~min}$ ), there was a much slower rate of clearance. $\mathrm{H}$ istorical data $(3,4,14)$ and the pilot studies in our patients $(n=4)$ without coughing (see METHODS) showed that there was little clearance.

The mean rates of whole-lung clearance for U TP and vehicle are summarized in Figure 3, which illustrates the clearance of isotope for both UTP and vehicle for the periods from 0 to $60 \mathrm{~min}$, and 0 to $120 \mathrm{~min}$ after inhalation from $\mathrm{t}=0$ to $60 \mathrm{~min}$ : of the radionuclide marker. $M$ ean clearance rates were significantly greater after inhalation of UTP, at $0.40 \pm 0.07 \% / \mathrm{min}$ for UTP versus $0.26 \pm 0.04 \% / \mathrm{min}$ for vehicle $(p=0.01)$. The difference was maintained for the subsequent 60 minutes of study; the mean clearance from 0 to 120 min was also greater after UTP, at $0.38 \pm 0.05 \% / \mathrm{min}$ as compared with $0.25 \pm$ $0.04 \% / \mathrm{min}$ for vehicle $(p=0.02)$. The retention of particles at $24 \mathrm{~h}$ was similar in both the placebo and U TP groups.

We tested whether the effect of UTP in enhancing clearance during cough could reflect confounding technical vari-

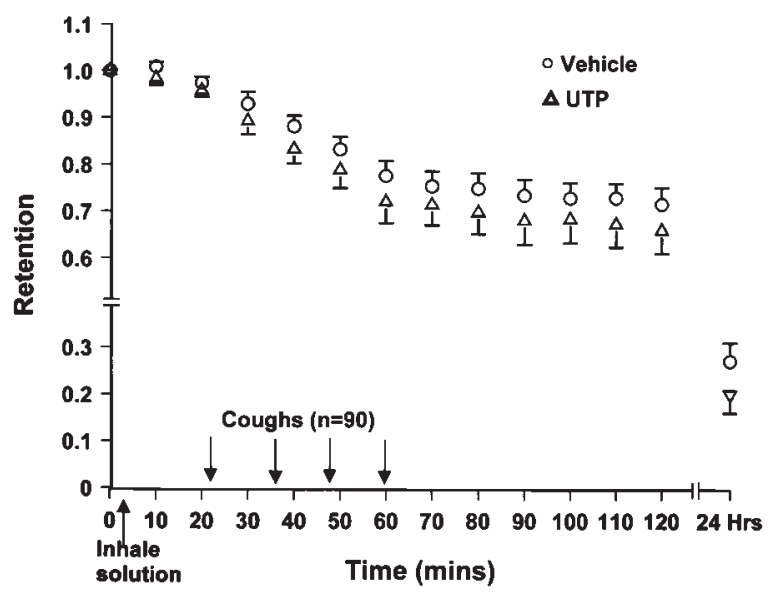

Figure 2. Whole-lung clearance ( \pm SEM) of radiolabeled particles over the entire study period for subjects $(n=12)$ with PCD after inhalation of UTP (triangles) and vehicle (circles). 


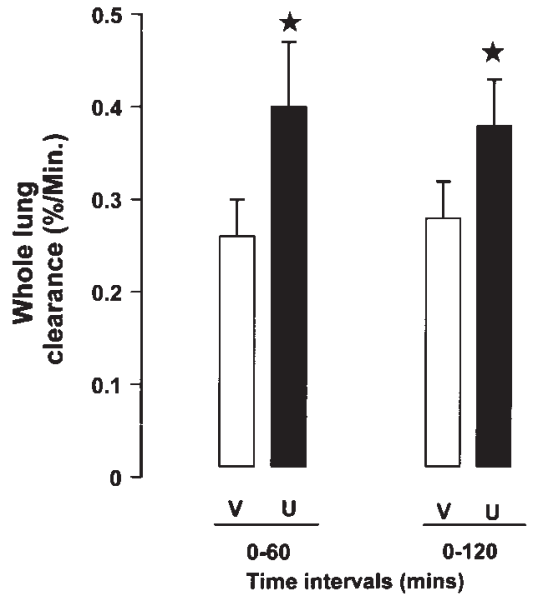

Figure 3. Whole-lung clearance of radiolabeled particles (\% of original isotope cleared per minute \pm SEM) for the periods $t=0$ to $60 \mathrm{~min}$ and $\mathrm{t}=0$ to $120 \mathrm{~min}$ after inhalation of UTP $(U)$ and vehicle (V). (* Different from vehicle $p<0.05$.)

ables. Initial deposition patterns (i.e., C/P ratios) were well matched on both study days (mean C/P on vehicle day: $2.37 \pm$ 0.3 , and on UTP day $=2.42 \pm 0.2$ ). The mean number of spontaneous coughs from 0 to $60 \mathrm{~min}$ was not significantly different on the UTP study day than on the vehicle day (19.4 \pm 4.8 for UTP versus $11.8 \pm 2.7$ for vehicle, $p=0.13)$. In the stepwise entry multivariate analysis, only UTP versus vehicle predicted the difference in clearance for both the 0 to $60 \mathrm{~min}$ and the 0 to 120 min time periods on the two study days $(p<0.05)$. $\mathrm{N}$ one of the other variables ( $C / P$ deposition ratio, number of spontaneous coughs, or PFR of controlled coughs) were significant dependent variables for clearance from either 0 to 60 min or 0 to $120 \mathrm{~min}$. Further, the changes in clearance during cough as a result of UTP inhalation were not predicted by any of the characteristics of the subjects participating in the study, such as lung function, age, or gender.

Interestingly, the mean PFR of controlled coughs was slightly higher after inhalation of U TP than after inhalation of vehicle at $4.7 \pm 0.07 \mathrm{~L} / \mathrm{s}$ versus $4.3 \pm 0.08 \mathrm{~L} / \mathrm{s}(p=0.01)$. The study was conducted in a double blind manner, and an investigator and the subject monitored each controlled cough on an oscilloscope to attempt to match the cough efforts (and thus peak flows) on each occasion. When entered into a separate multivariate analysis, this difference in cough PFR was predicted by both the study solution given on that day ( $p=$ $0.002)$, and the number of spontaneous coughs on that day $(p=$ $0.04)$.

In addition to analyzing the effects of UTP on whole-lung clearance during cough in the study subjects, we also assessed whether any of the characteristics of the subjects were predictive of baseline (i.e., after vehicle) clearance during cough. In a multivariate analysis of mean baseline clearance during cough through 60 min, only $\mathrm{FEV}_{1}$ (\% predicted) significantly predicted baseline clearance during cough $(r=0.59, p=0.04)$. There was no relationship between: (1) the number of spontaneous coughs; (2) the mean PFRs of controlled coughs normalized to the subjects lung volume; (3) age; or (4) gender. This analysis suggests that PCD patients with better lung function can more easily clear secretions by cough. This relationship was evident despite the association of a decreasing $\mathrm{FEV}_{1}$ with a higher $C / P$ ratio ( $F E V_{1} \%$ predicted versus $C / P: r=$ $0.68)$, which would tend to favor increased clearance (20).
TABLE 1

ION CONTENT AND BIORHEOLOGIC FEATURES OF AIRWAYS SECRETIONS FROM PATIENTS WITH PRIMARY CILIARY DYSKINESIA AFTER ACUTE AEROSOL DOSING WITH VEHICLE AND URIDINE-5'-TRIPHOSPHATE

\begin{tabular}{lccc}
\hline Parameter & $\begin{array}{c}\text { Vehicle } \\
(\mathrm{n}=8)\end{array}$ & $\begin{array}{c}\text { UTP } \\
(\mathrm{n}=8)\end{array}$ & Normal Values $^{\dagger}$ \\
\hline Avg Log G, 1 rad/s & $2.20 \pm 0.14$ & $2.00 \pm 0.1$ & $2.17 \pm 0.08$ \\
Cough-clearance index & $1.52 \pm 0.17$ & $1.74 \pm 0.15$ & $1.52 \pm 0.03$ \\
Mucociliary-clearance index & $0.89 \pm 0.04$ & $0.95 \pm 0.02$ & $0.91 \pm 0.02$ \\
$\mathrm{Na}^{+}$content, mEq/L & $125.0 \pm 8.3$ & $126.0 \pm 8.4$ & $\mathrm{~N} / \mathrm{A}$ \\
$\mathrm{Cl}^{-}$content, $\mathrm{mEq} / \mathrm{L}^{*}$ & $98.0 \pm 11.71$ & $100.0 \pm 3.80$ & $\mathrm{~N} / \mathrm{A}$ \\
\hline
\end{tabular}

Definition of abbreviation: N/A = not available.

Avg Log $\mathrm{G}$ is an index of mechanical impedance of sputum.

All values mean $\pm \mathrm{SEM}$.

$*_{\mathrm{n}}=5$.

${ }^{\dagger}$ Normal values shown for comparison (32).

\section{Clearance during Cough (Peripheral Lung)}

In contrast to the data for the whole lung, clearance during cough for the peripheral lung was not significantly different after the inhalation of UTP and vehicle $(0$ to $60 \mathrm{~min}: 0.09 \pm$ $0.03 \% / \mathrm{min}$ for vehicle, compared with $0.09 \pm 0.04 \% / \mathrm{min}$ for UTP; 0 to $120 \mathrm{~min}: 0.17 \pm 0.04 \% / \mathrm{min}$ for vehicle versus $0.17 \pm$ $0.04 \% / \mathrm{min}$ for UTP [mean \pm SE M ]).

\section{Sputum Production Rate and Lung Symptoms}

The mean weight of sputum produced after U TP tended to be greater than after vehicle $(3.40 \pm 0.17 \mathrm{~g}$ for UTP versus $2.95 \pm$ $0.50 \mathrm{~g}$ for vehicle, $p=0.3$ ). The sputum production rate in those patients also tended to be faster after UTP, at $0.39 \pm$ $0.07 \mathrm{~g} / \mathrm{min}$ versus $0.27 \pm 0.09 \mathrm{~g} / \mathrm{min}$ after vehicle $(\mathrm{p}=0.08)$. A mong the eight patients who completed the questionnaire after aerosol dosing, we could discern no difference in severity of cough, chest tightness, or wheezing. Four of the eight patients noted that sputum was easier to produce after UTP, one thought it was easier to produce after vehicle, and three could discern no difference in ease of expectoration after either solution. B ecause the questionnaire was not designed to be rigorously quantitative, the data were not subjected to statistical analysis.

\section{Sputum Rheology and Ion Content}

The ion content $\left(\mathrm{Na}^{+}\right.$and $\left.\mathrm{Cl}^{-}\right)$and indices of rheology of sputum are given in Table 1 for the eight subjects for whom matched samples were available. There was no difference between the two treatment groups in ion content, or in any of the rheologic indices: A vg Log G, clearance during cough index, or mucociliary index.

\section{Acute Safety}

No acute adverse effects were noted in any of the measured safety parameters ( $\mathrm{HR}, \mathrm{Sa}_{\mathrm{O}_{2}}$, blood pressure) in the nine subjects from whom data were obtained after administration of aerosolized UTP. A small decrease in $\mathrm{Sa}_{2}$ (from $96.3 \%$ to $95.6 \%$ ) was noted after inhalation of both UTP and vehicle and represented a significant change from baseline. A Ithough these changes following both UTP and vehicle reached statistical significance, they were not felt to be of any clinical significance. No arrhythmias were noted during the ECG monitoring, apart from a sinus tachycardia on both study days in one individual. This individual was noted to have the lowest $\mathrm{FEV}_{1}$ of the group ( $1.24 \mathrm{~L}, 43 \%$ predicted), and it was felt that the tachycardia was a manifestation of clinical status rather than 
of any drug effect. O ne subject noted slight chest pain and "stomach upset" after inhalation of both vehicle and UTP. These symptoms were not felt to be related to either study solution.

\section{DISCUSSION}

The pulmonary disease associated with defective MCC in $P C D$, for which there is no specific treatment, results in bronchiectasis $(5,21)$. Patients with PCD have cough as a prominent symptom, which serves as a compensatory mechanism for defective M CC. This may be a partly effective backup method for airway clearance in patients with PCD (3-5). In this pilot study, we showed that aerosolized UTP enhances clearance during cough in patients with PCD .

U TP represents a potential novel pharmacotherapy for airways disease, directed at modulation of ion transport and other components of the mucociliary apparatus (11, 22-24). A cting through extracellular $\mathrm{P}_{2} \mathrm{Y}_{2}$ receptors, UTP stimulates $\mathrm{Cl}^{-}$secretion via apical calcium-activated $\mathrm{Cl}^{-}$channels, induces goblet cell degranulation, and increases CBF in normal airway epithelia (25). Studies in normal subjects and in patients with CF (with UTP combined with amiloride) have shown that UTP improves M CC, presumably through the integrated effects of the stimulation of $C B F$, and secretion of mucins and liquid $(7,8)$. PCD provides a genetic model for attempting to test whether clearance during cough is favorably altered by UTP effects on mucin and ion secretion, rather than by effects that stimulate $C B F$, especially since in vitro data suggest that triphosphate nucleotides do not increase CBF (5).

In this study we elected to incorporate a series of controlled coughs early in the protocol (immediately after dosing) for two reasons. First, pilot observations of the study subjects suggested that aerosolization of vehicle tended to induce spontaneous cough, which would affect clearance measures. Second, the half-life of UTP on airway surfaces is likely to be limited after drug delivery (in vivo and in vitro studies suggest a half-time for clearance on the order of 15 to $30 \mathrm{~min}$ for the U TP concentrations relevant to this study [26, 27]). The metabolism of UTP is determined by ectonucleotidases present on airway surfaces, which rapidly degrade UTP. In the study of aerosolized UTP in normal subjects and CF patients, pharmacodynamic enhancement of M CC was evident for at least $50 \min (7,8)$. We therefore attempted to measure the effect of UTP during cough maneuvers during that time period.

The present study supported the hypothesis that after inhalation of U TP as compared with vehicle, there was an increase in the rate of clearance of radiolabeled particles during cough from the airways of the 12 subjects with PCD. The time periods during which the difference was noted are illustrative. A difference would have been most likely to have been evident during the period of controlled coughing (20 to $40 \mathrm{~min}$ ) rather than from 60 to 120 min, when most subjects did not cough. In those who did cough during this latter period, there was no difference in the mean number of coughs on either study day.

It is noteworthy that the clearance during cough was not significantly different with UTP and with vehicle for peripheral regions of the lungs of these PCD patients. In contrast, a previous study in patients with CF showed that the effect of UTP with amiloride on M CC was most notable in the peripheral regions of the lung (8). Since in the current study the deposited radionuclide was mainly in central airways (as indicated by the high $\mathrm{C} / \mathrm{P}$ ratios) and clearance during cough is dominant in the central airways, the main effect of UTP in enhancing whole-lung but not peripheral clearance in PCD is not surprising.
It is clear that other factors did not influence clearance during these studies. The $\mathrm{C} / \mathrm{P}$ ratios following the inhalation of $\left[{ }^{99 m \mathrm{~T}} \mathrm{C}\right] \mathrm{Fe}_{2} \mathrm{O}_{3}$ particles reflect the pattern of radionuclide deposition, and a higher $\mathrm{C} / \mathrm{P}$ ratio means more marker deposited in central (larger, proximal) airways. In this study, the C/P ratios were well matched on both study days, and the $\mathrm{C} / \mathrm{P}$ ratio did not exert a significant effect when introduced into the multivariate analysis (i.e., the effect of UTP on clearance during cough was still significant when the $C / P$ ratio was factored into the analysis). A lthough the number of spontaneous coughs tended to be slightly higher on the UTP than on the vehicle day, this did not have a significant effect on clearance during cough when subjected to multivariate analysis. For the variable of controlled coughs, we had the subjects monitor their own flow patterns and mimic these patterns for each series of coughs, while recording the peak flow of each controlled cough. When entered into the multivariate analysis, the mean peak flow for all subjects on each study day did not have a significant influence on the effect of UTP in improving clearance during cough.

A $n$ interesting observation was that the mean PFR was significantly increased on the UTP day as compared with the vehicle day ( $9 \%$ higher following U TP). This raises the possibility that the improved peak flow and altered airway mechanics seen with UTP may have improved the clearance of isotope, either by chance alone or as a direct result of the UTP inhalation. When entered into a simple correlation analysis in addition to the multivariate analysis described earlier, peak flow did not predict the difference in clearance at either $30 \mathrm{~min}$ or $60 \mathrm{~min}$, suggesting that improved PFRs did not cause the faster rate of clearance. The study was done in a double blind manner, and the subjects matched their efforts in producing controlled coughs on the two study days as much as possible, nor were there any controlled coughs during administration of aerosol. This argues against the improved PFR s of the controlled coughs after UTP occurring by chance alone. Furthermore, UTP has not been noted to be a bronchodilator in previous studies; if anything, small decrements in $\mathrm{FEV}_{1}$ and mean maximal expiratory flow measurements have been noted in both normal subjects and in patients with CF $(7,8)$. Thus, it is unlikely that U TP caused the improvement in airway mechanics directly. A speculative explanation for the improved PFR s following U TP is enhanced clearance of secretions early in the cough period (i.e., during spontaneous coughing), with better airflow mechanics. This hypothesis is supported by A NOVA of PFR as a function of UTP versus vehicle $(p=0.002)$ and of the number of spontaneous coughs $(p=0.04)$.

The actions of U TP in improving clearance during cough in $P C D$ are likely to reflect alterations in the volume and biorheology of airway secretions, since clearance during cough is a function of the depth of the periciliary fluid as well as of the rheology of the fluid layer $(17,28,29)$. U TP increases the volume of airway surface liquid, which probably does improve clearance of secretions during cough (30). B oth the periciliary and gel layers are probably likely cleared together, although whether this specifically happens with clearance during cough in PCD has not been tested (31). The measured ion contents of a small number of sputum samples in this study were not significantly different from one another, but the ion composition (tonicity) of sputum might not change if the water permeability is sufficient for the osmolarity to equilibrate with that of the isotonic submucosal liquid. The absence of any change in rheology may reflect the small number of matched samples available for statistical analysis, or the possibility that the changes were modest and not detected. H owever, it is interesting to note that the indices of rheology after administration of 
vehicle in these samples from patients with $P C D$ were within the previously reported normal ranges, and that clearance during cough tended to become supranormal after administration of UTP (32). Patients with CF, on the other hand, have abnormal indices of rheology at baseline (33).

In summary, UTP can safely be given by aerosolized delivery to patients with PCD, and is well tolerated. Whether the acute improvement in clearance of isotope during cough after such treatment translates into a meaningful clinical benefit remains to be seen $(4,34)$. The enhanced clearance of particles after U TP inhalation, with improved airway mechanics (PFR S), coupled with a tendency toward easier and more rapid sputum production, suggest that further clinical studies of this class of agents are warranted.

Acknowledgment: The authors would like to thank Joseph Robinson and Clay Gipson for assistance in performing the analyses of sputum samples.

\section{References}

1. A fzelius, B. A . 1976. A human syndrome caused by immotile cilia. Science 193:317-319.

2. Eliasson, R ., B. M ossberg, P. Camner, and B. A . A fzelius. 1977. The immotile cilia syndrome: a congenital ciliary abnormality as an etiologic factor in chronic airways infection and male sterility. N. E ngl. J. M ed. 297:1-6.

3. R ossman, C. M., J. B. Forrest, R. E. R uffin, and M. T. Newhouse. 1980. Immotile cilia syndrome in persons with and without Kartagener's syndrome. A m. Rev. Respir. D is. 121:1011-1016.

4. Camner, P., B. M ossberg, and B. A . A fzelius. 1983. M easurements of tracheobronchial clearance in patients with immotile cilia syndrome and its value in differential diagnosis. E ur. J. Respir. D is. 64:57-63.

5. G reenstone, M., A . R utman, A . D ewar, I. M ackay, and P. J. Cole. 1988. Primary ciliary dyskinesia: cytological and clinical features. Q. J. M ed. 67:405-430.

6. Wanner, A ., M. Salathe, and T. G . O 'R iordan. 1996. State of the art: mucociliary clearance in the airways. A m. J. Respir. Crit. Care M ed. 154: 1868-1902.

7. Bennett, W. D., K. N. Olivier, K. L. Zeman, K. W. Hohneker, R. C. B oucher, and M.R. K nowles. 1996. E ffect of uridine-5-triphosphate plus amiloride on mucociliary clearance in adult cystic fibrosis. A m. J . Respir. Crit. Care M ed. 153:1796-1801.

8. Olivier, K. N., W. D. B ennett, K. W. H ohneker, K. L. Zeman, L. J. Edwards, R . C. B oucher, and M. R. K nowles. 1996. A cute safety and effects on mucociliary clearance of aerosolized uridine-5-triphosphate \pm amiloride in normal adults. A m. J. Respir. Crit. Care M ed. 154:217-223.

9. L ethem, M.I., M . L. D owell, M . V anScott, J. R. Y ankaskas, T. M . E gan, R. C. B oucher, and M. R. Knowles. 1993. Nucleotide regulation of goblet cells, in human airway epithelial explants: normal exocytosis in cystic fibrosis. A m. J. Respir. Cell M ol. Biol. 9:315-322.

10. Lansley, A. B., M. J. Sanderson, and E. R. Dirksen. 1992. Control of the beat cycle of respiratory tract cilia by $\mathrm{Ca}^{2+}$ and CA M P. A m. J. Physiol. 263:232-242

11. Knowles, M. R., L. L. Clarke, and R. C. B oucher. 1991. A ctivation by extracellular nucleotides of chloride secretion in the airway epithelia of patients with cystic fibrosis. N. Engl. J. M ed. 325:533-538.

12. Carson, J. L., and A. M. Collier. 1988. Ciliary defects: cell biology and clinical perspectives. A dv. Pediatr. 35:139-166.

13. Wales, K. A ., H. Petrow, and D. B. Y eates. 1990. Production of ${ }^{99 \mathrm{~m}} \mathrm{TC}$ labelled iron oxide aerosols for human lung deposition and clearance studies. Int. J. A ppl. Rad. I sotopes. 31:689-694.
14. R uusa, J., M. Svartengren, K. Philipson, and P. Camner. 1993. Tracheobronchial particle deposition and clearance in immotile cilia syndrome patients. J. A erosol. M ed. 6:89-98.

15. Puchelle, E., J. M. Tournier, J. M. Z ahm, and P. Sadoul. 1984. R heology of sputum collected by a simple technique limiting salivary contamination. J. L ab. Clin. M ed. 103:347-353.

16. King, M., and P. T. M acklem. 1977. R heologic properties of microliter quantities of normal mucus. J. A ppl. Physiol. 42:797-802.

17. K ing, M., G. B rock, and C. Lundell. 1985. Clearance of mucus by simulated cough. J. A ppl. P hysiol. 58:1776-1782.

18. King, M ., B. Dasgupta, R. Tomkiewicz, and N. E. B rown. 1997. R heology of cystic fibrosis sputum after in vitro treatment with hypertonic saline alone and in combination with recombinant human deoxyribonuclease 1. A m. J. Respir. Crit. Care M ed. 156:173-177.

19. L eith, D. E ., J. P. B utler, and S. L. Sneddon. 1986. M echanics of breathing. In A . Fishman, editor. $\mathrm{H}$ andbook of Physiology. A merican Physiological Society, B ethesda, M D. 315-336.

20. Ilowite, J. S., G . C. Smaldone, R. Perry, W. D. B ennett, and W. M . Foster. 1989. The relationship between trancheobronchial clearance rates and the site of initial deposition in man. Arch. Environ. Health 44: 267-273.

21. Schidlow, D. V. 1994. Primary ciliary dyskinesia (the immotile cilia syndrome). A nn. A llergy 73:457-468.

22. Clarke, L. L., R . C. B oucher. 1992. Chloride secretory response to extracellular A TP in normal and cystic fibrosis nasal epithelia. A m. J. P hysiol. 263:C 348-C 356 .

23. B oucher, R. C. 1994. H uman airway ion transport: part 1. A m. J. Respir. Crit. Care Med. 150:271-281.

24. B oucher, R. C. 1994. H uman airway ion transport. part 2. A m. J. Respir. Crit. Care Med. 150:581-593.

25. Brown, H. A ., E. R . Lazarowski, R. C. B oucher, T. K. H arden. 1991. E vidence that UTP and A TP regulate phospholipase $C$ through a common extracellular 5 '-nucleotide receptor in human airway epithelial cells. M ol. Pharmacol. 40:648-655.

26. Regnis, J. A ., K. N. Olivier, S. J. M ason, C. E. Foy, J. Robinson, R. C. B oucher, and M. R. Knowles. 1995. U ridine-5'-triphosphate (UTP) clearance from canine airway surfaces and metabolism in the systemic vasculature (abstract). A m. J. Respir. Crit. Care M ed. 151:A 740.

27. L azarowski, E. R ., A . M. Paradiso, W. C. W att, T. K. H arden, and R. C. Boucher. 1997. UDP activates a mucosal-restricted receptor on human nasal epithelial cells that is distinct from the P2Y 2 receptor. P roc. Natl. A cad. Sci. U.S.A. 94:2599-2603.

28. Scherer, P. W . 1981. M ucus transport by cough. Chest 80(Suppl.):830-833.

29. Benali, R ., D. Pierrot, J. M. Zahm, S. de B entzmann, and E. Puchelle. 1994. E ffect of extracellular A TP and UTP on fluid transport by human nasal epithelial cells in culture. A m. J. Respir. Cell M ol. B iol. 10: 363-368.

30. Jiang, C., W. E. Finkbeiner, J. H. Widdicombe, P. B. M cCray, and S. S. M iller. 1993. A Itered fluid transport across airway epithelium in cystic fibrosis. Science 262:424-427.

31. M atsui, H ., S. H. R andell, S. W. Peretti, C. W. D avis, and R. C. B oucher. 1998. Coordinated clearance of periciliary liquid and mucus from airway surfaces. J. Clin. Invest. 102:1125-1131.

32. Jeanneret-G rossjean, A ., M. King, M. C. Michoud, H. Liote, and R. A myot. 1988. Sampling technique and rheology of human tracheobronchial mucus. A m. Rev. Respir. D is. 137:707-710.

33. K nowles, M. R., N. L. Church, W. E. W altner, J. R. Y ankaskas, P. G illigan, M. King, L. J . E dwards, R. W. H elms, and R . C. B oucher. 1990. A pilot study of aerosolized amiloride for the treatment of lung disease in cystic fibrosis. N. E ngl. J. M ed. 322:1189-1194.

34. Camner, P. 1988. How important is mucociliary clearance? Exp. L ung Res. 14:423-429. 